\title{
Novel Approach and Data Analysis of Cane Juice Centrifugation in Sugar Industry
}

\author{
Ms. Amruta Bijwar \\ Research Scholar, \\ Department of Instrumentation Engineering, Amravati \\ amrutabijwar@gmail.com
}

Abstract:

Centrifugation is one of the paramount unit operations in the sugar industry. Conventionally it is used after thickening of the cane juice, i.e. at a very high viscosity range. The authors are of the view that a sedimentation centrifuge will have the most suitable. The design features of centrifugals from batch to continuous types have been studies extensively, their operational parameters have also been discussed with practical application by several workers. Apart from centrifugation, the mechanical separation also plays a significant role for removing impurities obtain a comparatively purified product, Screening is also a method employed in various forms in the sugar industry. The speed maintains could be around $8000 \mathrm{rpm}$ in the range of $70-75 \%$ mud moisture. The scroll conveyor in this type of centrifuge can arrest suspension particles. The size range of 1$2 \mu \mathrm{m}$. It can have a wide range of feed flow, which can be estimated on the basis of a fullscale. All these points as discussed for a beneficial adoption of centrifugation of cane juice in the sugar industry.

Keywords; Sugar, Cane juice, Centrifugation, etc.

\section{INTRODUCTION}

The selection of centrifuge for the specific type of suspension needs some basic data. The particles, which are present in different sizes, their distribution in the medium, dynamic viscosity, density etc. are the main guidelines. The literature reveals that centrifugation of can juice was carried out way back in 1917 but few process details are available. A continuous conveyor- discharge centrifuge, which is basically a scroll type, collects suspended solids by sedimentation mud continuously removes the liquid through separate outlets. It consists of a critical screw type conveyor which removes the deposited solids. The knowledge of such a unit operation has been utilized in the present study. The juice is subjected to centrifugation directly after milling of the cane. This treatment has been thought of particularly to clarify juices by removing the suspended particles, viz. silica, organic salts, etc. along with mud. In addition the colloidal particles can also be separated out and the colour factor thereby initially improved. This treatment significantly brings down the chemical load on the juice on its way to clarification. 

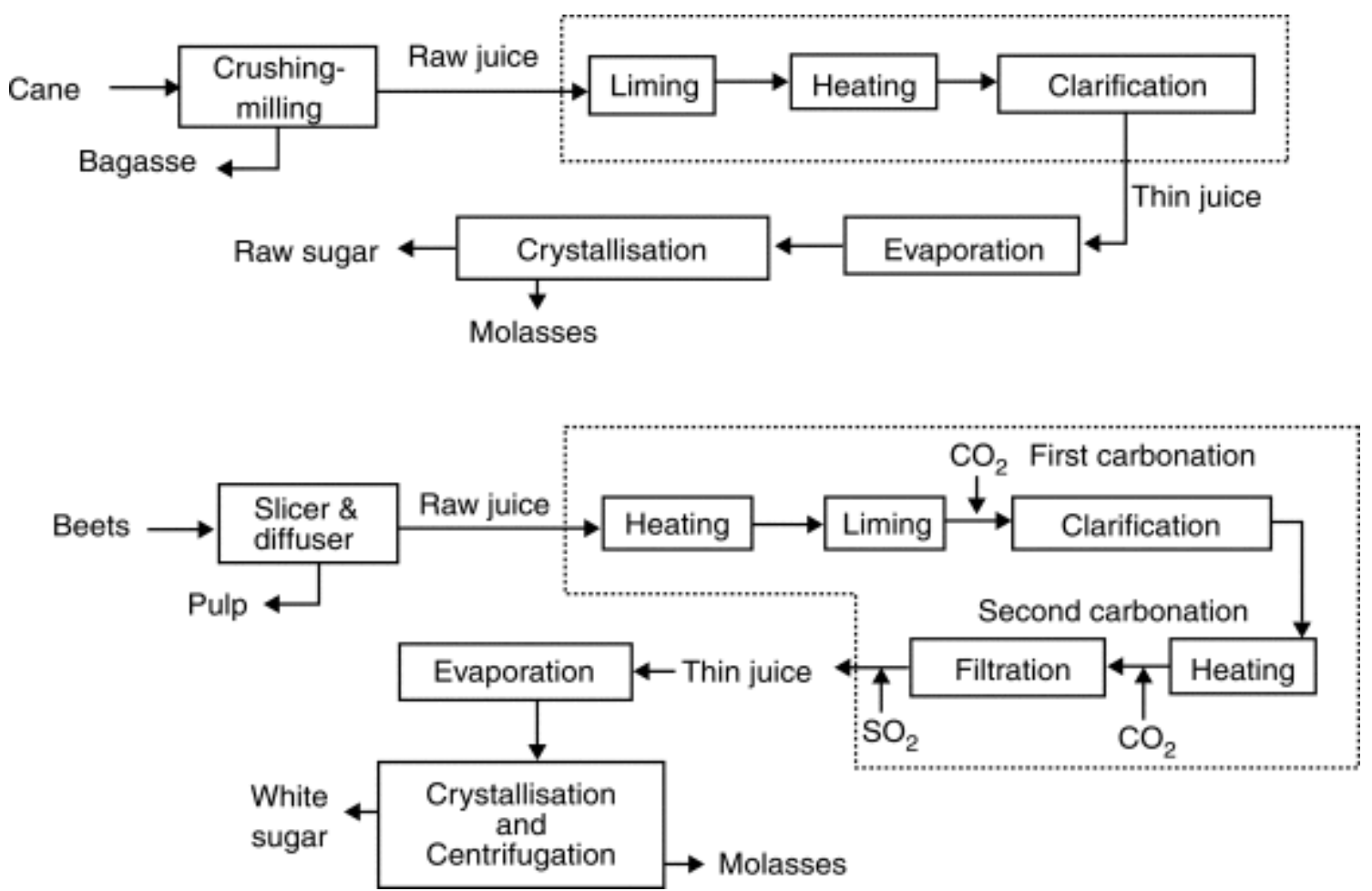

fig 1: cane juice centrifugation in sugar industry

\section{CANE JUICE CENTRIFUGATION}

Cane juice can be regarded as a suspension. Hence, solid-liquid separation could be made possible by increasing the gravitational force in a centrifugal separator. Sedimentation centrifuges are based on the principle of density difference. For industrial purposes, they can be designed on the basis of data collected in a laboratory bottle centrifuge. These data provide a better say for scaling-up to commercial centrifuges for cane juice treatment by calculating the theoretical capacity sector, i.e. using the sigma concept:

The $\Sigma$ value in sq.ft. for a bottle centrifuge is given by the equation

$$
\Sigma=\mathrm{Wv} / * 2 \mathrm{~g}(\operatorname{In} 2 \mathrm{r} 1 / \mathrm{r} 1+\mathrm{r} 2)]
$$

where

$\mathrm{r} 1=$ the radius in $\mathrm{ft}$ from the centrifuge axis to the liquid surface when the bottle is spinning. $\mathrm{r} 2=$ the radius to the bottom of the bottles

$\mathrm{w}=$ angular velocity of rotary motion $($ radians $/ \mathrm{sec})$.

$v=$ volume of the sample (cu.ft)

$\mathrm{g}=$ gravitational acceleration $\mathrm{ft} / \mathrm{sec}^{2}$. 
Furthermore, the value of $\mathrm{Q} / \sum$ can also be calculated using the following expression:

$$
\mathrm{Q} / \sum=2 \mathrm{~g} \operatorname{In}(2 \mathrm{r} 1 / \mathrm{r} 1+\mathrm{r} 2) / \mathrm{w}^{2} \mathrm{t}
$$

where

$\mathrm{Q}=$ flow rate in cu.ft/sec through the

centrifuge, and $\mathrm{t}=$ observed

sedimentation time required in seconds.

The preliminary calculations for the proposed machines are based on the information gatered from a bottle centrifuge or a laboratory model.

Another improvement factor is the residual moisture content. The variation range of this value is quite noticeable. The value is greatly influenced by the $\mathrm{g}$ factor. Haruni predicted the following

empirical relation:

$$
\mathrm{R}-\mathrm{Rm}=\mathrm{C}(\mathrm{Nm}-\mathrm{N})^{\mathrm{a}}
$$

where

$\mathrm{R}=$ residual moisture content ( $\mathrm{g} / \mathrm{g}$ dry solids) obtained at $\mathrm{N} \mathrm{rpm}$

$\mathrm{Rm}=$ residual moisture found by spinning at the deposition speed $\mathrm{Nm} \mathrm{C}$ and a are empirical constants valid only when $\mathrm{Nm}>\mathrm{N}$.

\section{DATA ANALYSIS}

It is quite interesting to note from Table I that the centrifugal effect on the purity is negligible. This clearly reveals that suspended particles along with organic salts are discharged with the mud whereas it fails to affect the dissolved solids. Secondly, $\mathrm{pH}$ and temperature almost remain the same, It is obvious that no chemical change is taking place. The temperature rise of $1^{0} \mathrm{C}$ may be due to the closed centrifuge chamber and resultant restricted heat dissipation, regarding the rpm and degree of separation, i.e. attainable $\mathrm{g}$ at the bottle tip, both factors will have to be optimized when switching over to a commercial scale as discussed in the earlier part. 
Table I

\begin{tabular}{|l|c|c|c|c|c|}
\hline MEDIUM & $\begin{array}{l}\text { PURI } \\
\text { TY }\end{array}$ & PH & $\begin{array}{l}\text { TEMPERATU } \\
\text { RE, }\end{array}$ & $\begin{array}{l}\text { SPEED, } \\
\text { RPM }\end{array}$ & $\begin{array}{l}\text { ATTAINABLE } \\
\text { G' }\end{array}$ \\
\hline $\begin{array}{l}\text { CANE } \\
\text { JUICE }\end{array}$ & 76.2 & $4.7-5.0$ & 32 & - & - \\
\hline TREATED & & & & & \\
\hline JUICE & 75.3 & $4.6-5.0$ & 33 & 6200 & 2200 \\
\hline
\end{tabular}

On examining Table II, the reduction in relative viscosity is approximately $20 \% \pm 5.0 \%$. The mixed juice may be treated as a suspension. And this reduction may be attributed to the change in concentration of the medium. Finally, the physical appearance of the treated juice is quite brilliant with a tinge of turbidity containing a small amount of floating bagacillo. Around 20\% ICUMSA units in colour improvement is evident from Table II, The ICUMSA colour of clear juice of the same factory where the said experiments were carried out was also measured and this value was found to be quite near to the value for treated juice. In Indian conditions, the dirt correction plays an important factor in the analysis of the sugar balance. Instead of the conventional method, if the centrifuged juice is directly weighed, the sugar balance report could be made more accurate. This is an additional advantage of the treatment.

\section{Table II}

\begin{tabular}{|c|c|c|c|}
\hline MEDIUM & $\begin{array}{c}\text { VISCOSITY } \\
\text { CPS }\end{array}$ & $\begin{array}{c}\text { CLARIT } \\
\text { Y }\end{array}$ & ICUMSA UNITS \\
\hline CANE JUICE & 1.26 & 42.8 & 4210.00 \\
\hline $\begin{array}{c}\text { TREATED } \\
\text { JUICE }\end{array}$ & 1.05 & 13.6 & 3256.00 \\
\hline CLEAR JUICE & 1.03 & 10.5 & 2865.00 \\
\hline
\end{tabular}

\section{CONCLUSION}

In this paper we have discussed about centrifugation of cane juice. The operational parameters such as removal of suspended particles, clarity and ICUMSA colour of the 
centrifuged juice, dirt correction and advantages of the process have been elaborately studied.

\section{REFERENCES}

[1] Premalatha M (2008) Efficient cogeneration scheme for sugar industry. Journal of Scientific \& Industrial Research 67:239-242

[2] Birru (2007) Investigation of the potential of sugar cane industries (MSc thesis)

[3] Marianela Cordovés Herrera(1999)."CaneSugar and The environment-Cuba conference". Available at http://www.fao.org/docrep/005/X4988E/x4988e01.htm. Accessed March 2012

[4] Ingaramo A, Heluane H, Colombo M, Cesca M (2009) Water and wastewater eco-efficiency indicators for the sugar cane industry.Journal of Cleaner Production 17 : 487-495

[5] Kamate CS and Gangavati BP (2009) Cogeneration in Sugar Industries: Technology Options and Performance Parameters-A Review, Cogeneration \& Distributed Generation Journal, 24:4, 633, DOI:10.1080/15453660909595148

[6] Raghu RJ, Banerjee R(2003)Energy and cogeneration targeting for a sugar factory. Applied Thermal Engineering 23:1567-1575

[7] Ensinas VA, Lozano MA, Serra LM (2007) Analysis of process steam demand reduction and electricity generation in sugar and ethanol production from sugarcane. Energy conversion \& Management 48:2978-2987

[8] Lavarack BP, Hodgson JJ, Broadfoot R, Vigh,S and Venning J (2004) Improving the energy efficiency of sugar factories: Case study for pioneer mill Proc. Aust. Soc. Sugar Cane Technology: 26

[9] ABB (2010) ACS 1000 variable speed drives increase energy efficiency at sugar plant-case study. Available http://www05.abb.com/global/scot/scot216.nsf/veritydisplay/46ae6cf38fa1228bc12577e40056e2 1d/\$file/CS_Sugar\%20RevB_lowres.pdf

[10] Dias SOM, Modesto M, Ensinas VA, Nebra AS, Filho MR, Rossell VEC (2011) Improving bioethanol production from sugarcane: evaluation of distillation, thermal integration and cogeneration systems. Energy 36:6, 3691-3703

[11] Solomon S (2011) The Indian Sugar Industry: An Overview. Sugar Technology 13(4):255-265

[12] Keerthipala RA (2007) Sugar Industry of Sri Lanka: Major Issues and Future Directions for Development. Sugar Technology :9(1) 1-10

[13] Ethiopian sugar corporation. Available at http://www.etsugar.gov.et/

[14] Alonso-Pippo W, Luengo AC, Koehlinger J, Garzone P, Cornacchia G (2008) Sugarcane energy use- The Cuban case. Energy Policy $36: 2163-2181$

[15] Edward D (1981)Standard Fabrication Practices for Cane Sugar Mills. Amsterdam: Elsevier Scientific Pub. Co. ; New York: Elsevier Scientific Pub. Co. ; New York: Elsevier Scientific Pub. Co. ISBN0-444-41958-6;ISBN1-322-26407-4;ISBN1-4832-8967-2

[16] Costa, A. F. S.; Nascimento, V. R.; Amorim, J. D. P.; Gomes, E. A. S.; Araujo, L. M.; Sarubbo, L. A. Residue from the production of sugar cane: an alternative nutrient used in biocellulose production by Gluconacetobacter hansenii. Chemical Engineering Transactions, v. 64, p. 7-12, 2018. DOI: $10.3303 /$ CET1864002

[17] Hamerski, F. Study of variables in the process of carbonation of the broth of sugar cane. p. 148. Dissertation. Graduate degree in food technology. Federal University the Paraná, Curitiba, 2009. 